\title{
Pore pressure variation at constant confining stress on water-oil and silica nanofluid-oil relative permeability
}

\author{
Caspar Daniel Adenutsi ${ }^{1,2} \odot$. Zhiping $\mathrm{Li}^{1,2} \cdot$ Fengpeng Lai $^{1,2} \cdot$ Anthony Edem Hama ${ }^{3}$ Wilberforce Nkrumah Aggrey ${ }^{3}$
}

Received: 1 September 2018 / Accepted: 13 December 2018 / Published online: 21 December 2018

(c) The Author(s) 2018

\begin{abstract}
Studies on stress sensitivity of relative permeability in the laboratory were mostly carried out by varying overburden pressure at constant pore pressure (PP). However, in a real oilfield situation, changes in net stress are induced by changes in PP rather than overburden pressure. This research presents the effect of PP variation at a confining stress of $25 \mathrm{MPa}$ on water-oil and silica nanofluid-oil relative permeability curves. Results showed that, at low PP variations of $0.1,2$, and $5 \mathrm{MPa}$, two-phase flow parameters exhibited distinct trends. Thus, for water-oil relative permeability, initial water $\left(S_{\mathrm{wi}}\right)$ and residual oil $\left(S_{\text {or }}\right)$ saturations both decreased as PP increased. End-point oil $K_{\mathrm{ro}}\left(S_{\mathrm{wi}}\right)$ and water $K_{\mathrm{rw}}\left(S_{\mathrm{or}}\right)$ relative permeabilities both increased for water flooding. Similar trends were observed for nanofluid flooding. End-point mobility ratio and displacement efficiency both increased with increase in PP within this range for water and nanofluid flooding. At $10 \mathrm{MPa}$ PP, $S_{\mathrm{wi}}$ decreased compared to low PP variations, while $S_{\text {or }}$ increased significantly. Similar observation was made for nanofluid flooding except for $S_{\text {or }}$ which had moderate increment. End-point mobility ratio increased significantly for water flooding, but had a slight increase for nanofluid flooding compared to low PP variations. Displacement efficiency decreased for both water and nanofluid flooding compared to low PP variations. At the same PP, water-oil and nanofluid-oil relative permeabilities showed similar $S_{\mathrm{wi}}$ and $K_{\mathrm{ro}}\left(S_{\mathrm{wi}}\right)$ but differing $S_{\mathrm{or}}$ and $K_{\mathrm{rw}}\left(S_{\mathrm{or}}\right)$. The findings provide insights into the effect PP variation on relative permeability and would be important in flooding design considerations.
\end{abstract}

Keywords Steady-state method $\cdot$ Relative permeability $\cdot$ Stress sensitivity $\cdot$ Mobility ratio $\cdot$ Displacement efficiency

Electronic supplementary material The online version of this article (https://doi.org/10.1007/s13202-018-0605-6) contains supplementary material, which is available to authorized users.

Caspar Daniel Adenutsi

casdanad@hotmail.com

Zhiping Li

2002011671@cugb.edu.cn

Fengpeng Lai

laifengpeng@cugb.edu.cn

Anthony Edem Hama

aehama.coe@knust.edu.gh

Wilberforce Nkrumah Aggrey

aggreynkrumah@yahoo.com

1 School of Energy Resources, China University of Geosciences, Beijing 100083, People's Republic of China

2 Beijing Key Laboratory of Unconventional Natural Gas Geological Evaluation and Development Engineering, Beijing 100083, People's Republic of China

3 Core and Rock Properties Laboratory, Department of Petroleum Engineering, Kwame Nkrumah University of Science and Technology, PMB, Kumasi, Ghana

\section{Introduction}

Relative permeability curves are essential in reservoir engineering as they are used in numerical modeling, dynamic analysis, and reservoir performance predictions (Abdelazim 2016; Akhlaghinia et al. 2014; Li et al. 2015; Parvazdavani et al. 2017; Shi et al. 2018; Tian et al. 2015; Zhang et al. 2014). However, relative permeability depends on internal and external applied stresses. Production of hydrocarbons decreases pore pressure, while injection of fluids increases pore pressure. Therefore, in situ changes that occur during hydrocarbon production or pressure maintenance by fluid injection could have a substantial effect on reservoir performance. Thus, accurate understanding and knowledge of the state of stress acting on a reservoir during the life of a field would eliminate errors in reservoir engineering predictions.

Almost all the previous studies (Adenutsi et al. 2018; Ali et al. 1987; Fatt 1953; Gawish and Al-Homadhi 2008; Jones et al. 2001; Thomas and Ward 1972; Wilson 1956) on stress sensitivity of relative permeability curves read in the

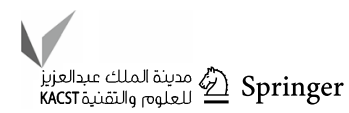


literature were conducted by varying confining stress, which simulates overburden pressure. However, in a real oilfield situation, changes in net stress due to hydrocarbon production or fluid injection operations are induced by changes in pore pressure rather than overburden pressure. Meanwhile, Al-Quraishi and Khairy (2005) studied the effect of pore pressure variation at a constant overburden pressure of 17.3 MPa on relative permeability by the unsteady state method. A back pressure valve in the core flooding rig was used to vary pore pressures at $0.1,3.5,6.9$, and $13.8 \mathrm{MPa}$, while injecting at a constant rate of $1.5 \mathrm{~mL} / \mathrm{min}$. This investigation was performed on Berea sandstones using crude oil and synthetic brine made of $3 \% \mathrm{NaCl}$. The study revealed a decreasing trend in oil relative permeability and minimal changes in water relative permeability as pore pressure was increased. The initial water saturation mainly decreased as pore pressure increased except at $13.8 \mathrm{MPa}$, but residual oil saturation showed a complicated trend. In addition, as pore pressure increased, both end-point oil and water saturations initially increased and subsequently decreased.

Research on the application of nanoparticles to increase hydrocarbon recovery is rife in literature and the mainly investigated nanoparticle is silica which has gained smallscale application in real oilfields (Afolabi and Yusuf 2018; Cheraghian 2015; Cheraghian and Hendraningrat 2016a, b; Ju et al. 2002, 2012; Ju and Fan 2009; Roustaei and Bagherzadeh 2015; Roustaei et al. 2013; Sun et al. 2017; Youssif et al. 2018; Zallaghi et al. 2018). However, research on the effect of nanoparticle on relative permeability is few. The previous studies concluded that silicon and aluminum oxide-based nanofluids cause changes in relative permeability curves due to wettability alteration (Amedi and Ahmadi 2016; Giraldo et al. 2013; Lu et al. 2017). Parvazdavani et al. (2014) applied polysilicon nanofluid and observed obvious changes in oil relative permeability but minor change in water relative permeability. In a recent study, Adenutsi et al. (2018) studied the effect of stress on relative permeability by varying confining pressure at a fixed pore pressure. The authors concluded that, for the sample that had adsorbed nanoparticle prior to subsequent stress increments, the effect of stress was dominated by the effect of nanoparticle adsorption. However, the effect of stress took precedence over nanoparticle adsorption on samples that had no nanoparticle adsorption prior to relative permeability measurements.

While much has not been read on the study on pore pressure variation on relative permeability, the available literature did not present any work on the application of nanofluids in the study of stress sensitivity of relative permeability curves with regards to pore pressure variation. This research presents findings on changes that occur on relative permeability curves by varying pore pressure at constant or fixed overburden pressure by employing the conventional water and oil as well as silica nanofluid and oil as displacing fluids. Moreover, silica nanofluid adsorption on pore walls was also studied by changes in NMR $\mathrm{T}_{2}$ distributions. Finally, the effect of pore pressure variation on end-point mobility ratio and displacement efficiency was investigated.

\section{Experimental materials and methods}

\section{Fluids}

In this investigation, kerosene (hereinafter referred to as oil) with density and viscosity of $0.7982 \mathrm{~g} / \mathrm{mL}$ and $1.48 \mathrm{cp}$ respectively at $25{ }^{\circ} \mathrm{C}$ was used. Deionized water with density and viscosity of $0.997 \mathrm{~g} / \mathrm{mL}$ and $0.89 \mathrm{cp}$, respectively, was used as a displacement fluid and the base medium for nanoparticle dispersion.

A hydrophilic nanoparticle powder (Zhengzhou Dongyao Nano Materials Co. Ltd., China) with single particle size of $7 \mathrm{~nm}$, which consists of $99.9 \%$ silicon dioxide, was used in this study (Fig. 1a). The silica nanoparticles were dispersed in deionized water using a high-speed mechanical stirrer and later with a sonicator for $90 \mathrm{~min}$ to produce a nanofluid of 0.05 wt.\% (Fig. 1b). The measured density and viscosity of the nanofluid were $1.035 \mathrm{~g} / \mathrm{mL}$ and $1.12 \mathrm{cp}$, respectively, at $25{ }^{\circ} \mathrm{C}$. Viscosities of fluids were measured by Brookfield
Fig. 1 a $\mathrm{SiO}_{2}$ nanoparticles and b 0.05 wt. $\% \mathrm{SiO}_{2}$ nanofluid
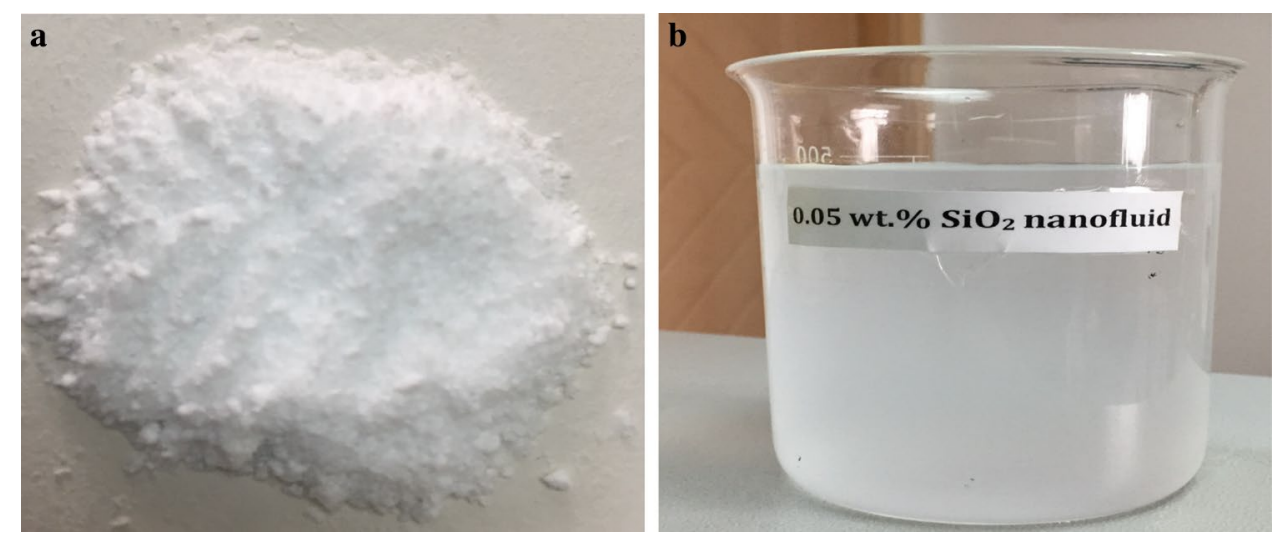
DV2T Viscometer (Brookfield Ametek, USA), as shown in the Online Resource, Fig. S1.

\section{Core samples and initial preparations}

Consolidated, artificial core samples were acquired from a Key State Laboratory at the China University of Petroleum, Beijing. The samples were prepared using the standard protocols and the preferential wetting characteristics of the fluids as tested on a glass plate were water wet at atmospheric conditions. The artificial cores were made of quartz sand, feldspar, and kaolinite which were reconstituted in a predetermined ratio by epoxy resin under pressure at room temperature for $12 \mathrm{~h}$ to obtain consolidated artificial cores.

Core permeability was controlled by increasing the ratio of small particles and aiding pressure. The air porosity and permeability were measured by KS-VI steady-state gas permeameter and porosimeter equipment (Jiangsu Hongbo Machinery Manufacturing Co. Ltd, China; Online Resource, Fig. S2). The properties and experiment type which they have been employed in are presented in Table 1.

In this work, core saturation process was done with JB-1 vacuum saturation equipment (Jiangsu Hongbo Machinery Manufacturing Co. Ltd, China, Online resource, Fig. S4) after which a pressure cell was used to ensure $100 \%$ water saturation. The samples were vacuumed for $24 \mathrm{~h}$ and then saturated with deionized water for $48 \mathrm{~h}$ with a pore pressure of $20 \mathrm{MPa}$. The vacuum saturation method usually resulted in about $92-96 \%$ water saturation. The samples were then saturated in a high-pressure cell for another $48 \mathrm{~h}$ at $30 \mathrm{MPa}$ pore pressure and the water saturation confirmed to be $100 \%$ by weight. This procedure was used for all saturations in this research to ensure full-sample saturation.

\section{Initialization of irreducible water saturation by the centrifuge technique}

Bioridge CSC-12 centrifuge (Bioridge Company, Shanghai, China; Online Resource. Fig. S3) was employed to measure air-water drainage capillary pressure curves of core samples according to standard reference SY/T 5346-2005. Core inlet water saturations were evaluated according to Hassler and Brunner (1945) and the details are presented in Online
Resource B.1. After the centrifuge experiment, the samples were dried in an oven at $105^{\circ} \mathrm{C}$ for $12 \mathrm{~h}$.

\section{Relative permeability measurement procedure}

The schematic of the core flooding rig used in relative permeability measurements is presented in Fig. 2 with a picture of the apparatus (LDY50-180, Jiangsu Hongbo Machinery Manufacturing Co. Ltd, China) in Fig. S5 of the Online Resource. Pore pressure was kept constant by means of a back pressure valve incorporated in the apparatus. The fluids exiting the core holder were received by the back pressure pump operated at constant pressure receive mode, so that a constant back pressure is maintained. Confining pressure was kept at $25 \mathrm{MPa}$ for all the experiments. Steady-state method was used in relative permeability measurements in accordance with experimental standard reference GB/T 28912-2012 and details presented in Online Resource B.2. Capillary end effect (CEE) was corrected using the Intercept Method as proposed by Gupta and Maloney (2016). Effective permeabilities at a predetermined pore pressure were normalized by absolute permeability to water, $K_{\mathrm{a}}$ (please refer to Table 5), measured at the same pore pressure, to obtain relative permeabilities.

\section{Relative permeability experiment types}

\section{Water-oil relative permeability measurements (Run 1)}

In this investigation, core samples F-1, F-2, F-3, and F-4 were used for $0.1,2,5$, and $10 \mathrm{MPa}$ pore pressures, respectively. The displacing fluids for this batch of experiments were deionized water and oil. After the relative permeability measurements, the core samples were cleaned by alternate extraction with hot toluene and methanol in a Soxhlet extractor (Online Resource, Fig. S6). The core samples were dried and re-saturated for the next batch of relative permeability measurements.

\section{Nanofluid-oil relative permeability measurements (Run 2)}

In this set of experiments, silica nanofluid and oil were used as displacement fluids. The same core samples were used for

Table 1 Core sample properties and type of experiment

\begin{tabular}{lllllll}
\hline Core sample & Length $(\mathrm{cm})$ & Diameter $(\mathrm{cm})$ & Porosity $(\%)$ & $\begin{array}{l}\text { Initial pore vol- } \\
\text { ume }(\mathrm{mL})\end{array}$ & $\begin{array}{l}\text { Klinkenberg perme- } \\
\text { ability }(\mathrm{mD})\end{array}$ & Experiment type \\
\hline F-1 & 5.52 & 2.55 & 18.74 & 5.3 & 75.0 & Run 1 and 2 \\
F-2 & 5.53 & 2.53 & 18.45 & 5.1 & 72.0 & Run 1 and 2 \\
F-3 & 5.57 & 2.53 & 18.10 & 5.1 & 77.6 & Run 1 and 2 \\
F-4 & 5.52 & 2.54 & 18.04 & 5.0 & 76.6 & Run 1 and 2 \\
\hline
\end{tabular}


Fig. 2 Schematic diagram of core flooding equipment

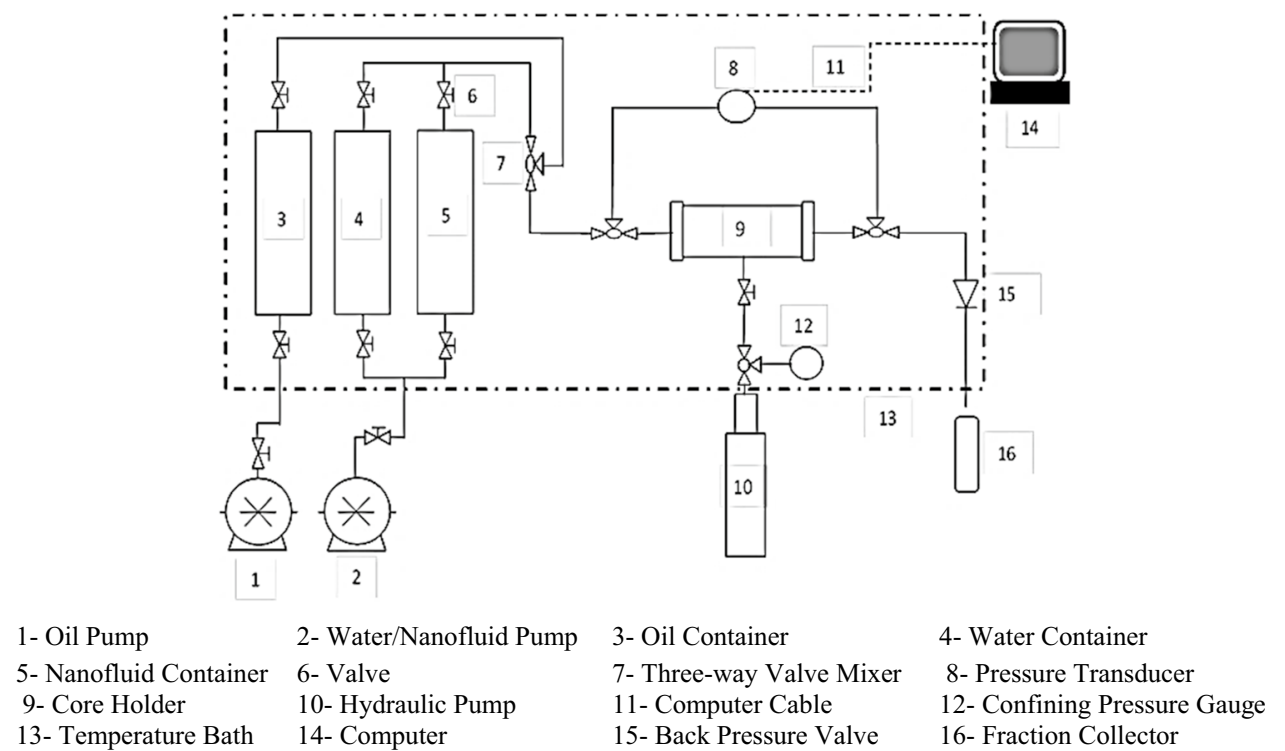

their respective pore pressures as in Sect. "Water-oil relative permeability measurements (Run 1)". However, deionized water was used in the saturation process and oil was used during the drainage process in flooding the core to $S_{\mathrm{wi}}$.

\section{NMR $\mathrm{T}_{2}$ distribution measurement}

Prior to each relative permeability measurement, NMR $\mathrm{T}_{2}$ distribution of the samples was measured at atmospheric condition with SPE-RE1-050 NMR spectrometer (Beijing SPEC S\&T Development Co. Ltd, China; Online Resource Fig. S7). Thus, prior to water-oil relative permeability measurements, NMR $\mathrm{T}_{2}$ distributions of all the core samples were measured, while they were fully saturated with deionized water. These NMR $\mathrm{T}_{2}$ distributions were called "Before water-oil". Prior to nanofluid-oil relative permeability, NMR $\mathrm{T}_{2}$ distributions of all the core samples were measured, while they were fully saturated deionized water. These NMR $\mathrm{T}_{2}$ distributions were called "Before nano-oil". The "Before nano-oil" data were also used as the NMR $\mathrm{T}_{2}$ distributions after water-oil relative permeability and called "After water-oil". This is because this NMR $\mathrm{T}_{2}$ distribution measurement precedes the nanofluid-oil relative permeability experiments, but follows that of water-oil relative permeability experiments. After nanofluid-oil relative permeability measurements, the core samples were cleaned, dried, and re-saturated with deionized water, and a final NMR $\mathrm{T}_{2}$ distribution was measured. These were called "After nanooil" NMR $\mathrm{T}_{2}$ distributions. By comparing these NMR $\mathrm{T}_{2}$ distribution curves, the effect of nanoparticle deposition in the core samples can be quantitatively evaluated. The magnetic field strength was $0.28 \mathrm{~T}$, the resonance frequency of the hydrogen proton was $12 \mathrm{MHz}$, and the main NMR measurement parameters included an echo spacing of $0.3 \mathrm{~ms}$, waiting time of $1000 \mathrm{~ms}$, echo numbers of 1024, scanning numbers of 64, and an environmental temperature of 34 . After the measurements, $\mathrm{T}_{2}$ distributions were computed by multi-exponential inversion of the echo data with 64 pre-set decay time logarithmically spaced from 0.01 to $10,000 \mathrm{~ms}$.

\section{Results and discussion}

\section{Establishment of initial water saturation in core samples}

Results of core average water saturation versus inlet capillary pressure are presented in Fig. 3. The inlet capillary pressure versus average water saturation curves were fitted by the least square method following a power law.

The results of experimental data curve fitting are presented in Table 2. Results of the power law curve fit showed strong relationship with experimental data with $R^{2}$ values ranging between 98.59 to and $99.44 \%$. This implied using a power law relationship is appropriate for the approximation of experimental data.

Figure 4 presents results of inlet water saturation versus inlet capillary pressure. The initial water saturation was chosen as the smallest water saturation that was independent of inlet capillary pressure (Table 3 ). The initial water saturations evaluated from core flooding were compared to that calculated from the centrifuge method to establish true initial water saturation in core samples.

The results revealed that the initial water saturations evaluated from core flooding were higher compared to the centrifuge method. While centrifuge experiments were carried out at atmospheric pressure, core flooding was carried out at high net effective stress. At higher stresses, 
Fig. 3 Inlet capillary pressure versus average water saturation: a F-1, b F-2, c F-3, and d F-4
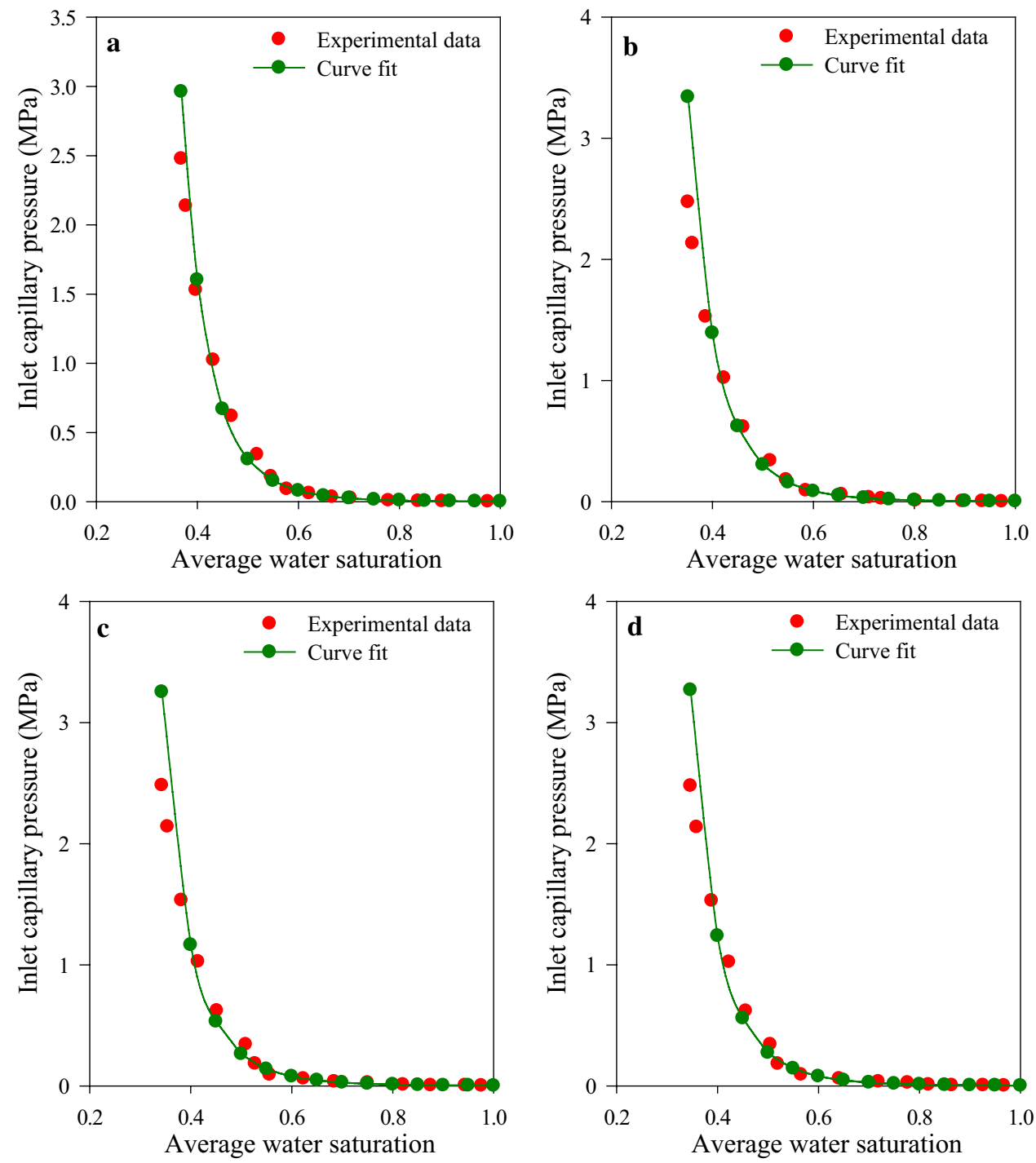

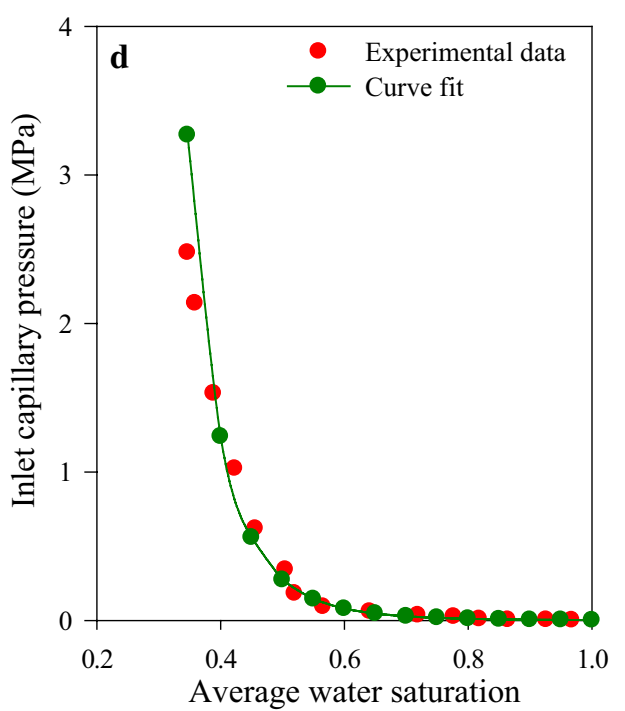

Table 2 Empirical constants from least square power law curve fit

\begin{tabular}{llll}
\hline Core sample & \multicolumn{2}{l}{ Empirical constants } & $R^{2}(\%)$ \\
\cline { 2 - 3 } & \multicolumn{1}{l}{$C_{1}$} & $C_{2}$ & \\
\hline F-1 & 0.0018 & -7.412 & 99.44 \\
F-2 & 0.0027 & -6.816 & 99.09 \\
F-3 & 0.0026 & -6.661 & 99.00 \\
F-4 & 0.0025 & -6.772 & 98.59 \\
\hline
\end{tabular}

pore volumes of core samples reduced (compare Tables 1, $5)$ which would ideally reduce pore radius. The wetting phase would readjust to occupy these reduced pores. In this investigation, flow rate was increased during the drainage process of core flooding experiments until no further water was produced. Thus, initial water saturations evaluated from core flooding represented true initial water saturations of core samples.

\section{Effect of nanoparticles on pore size distribution}

A $\mathrm{T}_{2}$ cut-off of $33 \mathrm{~ms}$ was used to separate small pores from big pores. The frequency amplitudes before and after the $\mathrm{T}_{2}$ cut-off were added to determine the area which these amplitudes occupy, respectively. The percentage changes in total pore, small pore, and big pore areas are evaluated and presented in Table 4 . The NMR $\mathrm{T}_{2}$ distributions are presented in Fig. 5, 6, 7, and 8 for core samples F-1, F-2, F-3, and F-4, respectively. The morphology of distributions of the samples was similar. The $\mathrm{T}_{2}$ distributions exhibited continuous bimodal characteristics in all the samples. The similarity in terms of morphology and amplitude of samples confirmed the reproducibility of the NMR experiments.

Overall, there had been low changes in samples flooded with water. The highest change being F-1, which showed $13.54 \%$ reduction in total pore area after water-oil relative 


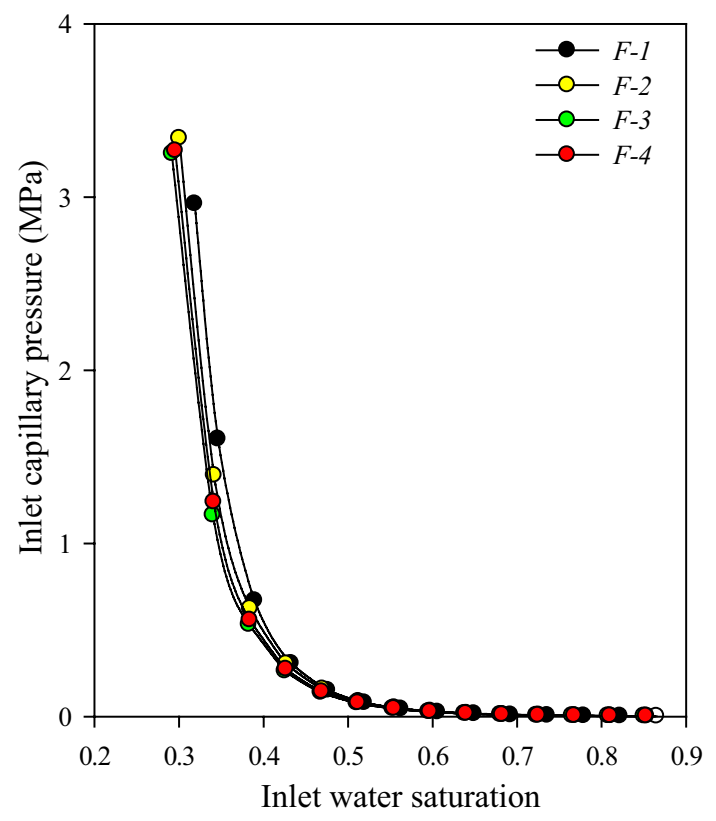

Fig. 4 Inlet water saturation versus inlet capillary pressure

Table 3 Initial water saturation from centrifuge and core flooding methods

\begin{tabular}{|c|c|c|c|}
\hline \multirow[t]{3}{*}{ Core sample } & \multicolumn{3}{|c|}{ Initial water saturation } \\
\hline & \multicolumn{2}{|c|}{ Centrifuge technique } & \multirow[t]{2}{*}{ Core flooding } \\
\hline & $\begin{array}{l}\text { Core average } \\
\text { (experimental } \\
\text { data) }\end{array}$ & $\begin{array}{l}\text { Core inlet } \\
\text { (approxima- } \\
\text { tion) }\end{array}$ & \\
\hline $\mathrm{F}-1$ & 0.3682 & 0.3185 & 0.3560 \\
\hline $\mathrm{F}-2$ & 0.3518 & 0.3002 & 0.3313 \\
\hline F-3 & 0.3428 & 0.2913 & 0.3168 \\
\hline F-4 & 0.3466 & 0.2958 & 0.3018 \\
\hline
\end{tabular}

permeability measurement. The rest of the core samples exhibited less than $7 \%$ change in total pore area after water-oil relative permeability measurements. The relative low changes could be due to the inability of the cores to fully recover after being subjected to different stress levels. The conspicuous reductions in total pore area with samples flooded with nanofluid could, therefore, be attributed to the attachment of nanoparticles to pore walls in the core samples.

After nanoparticle flooding in all samples, reduction in pore area of big pores was much higher than small pores. This meant that nanoparticles got attached or adsorbed to the pore walls. In addition, because of the density difference between moving nanoparticles and carrying fluid, nanoparticles could be retained in the pores due to gravity settling.
Another important observation was that after nanofluid flooding, reduction in big pore area, and in total pore area increased in order for samples F-1, F-2, and F-3, respectively. This could probably be due to the increase in pore area due to increase in pore pressure as the sample was under stress. The increase in pore area probably allowed more nanofluid to flow through which got deposited on pore walls and throats.

\section{Effect of pore pressure variation on water-oil relative permeability}

Figure 9 presents the effect of pore pressure on water-oil relative permeability curves. For the purposes of clear explanation, the ranges of pore pressures were classified into low pore pressures $(0.1,2,5 \mathrm{MPa})$ and relatively high pore pressure $(10 \mathrm{MPa})$. At low pore pressures, the curves showed a consistent trend (Fig. 9a). At relatively high pore pressure, relative permeability displayed a distinct behavior (Fig. 9b).

In this study, as pore pressure increased (decreasing net effective stress) within the low pore pressure range, oil relative permeability curves $\left(K_{\mathrm{ro}}\right)$ increased at constant saturation, while water relative permeability curves $\left(K_{\mathrm{rw}}\right)$ had minimal effects. As pore pressure increased, a fraction of larger pores probably increased which was evidenced as increase in pore volume (Table 5). It, therefore, became easier to mobilize oil out of larger pores due to decrease in capillary entry pressure. Wetting phase occupies relatively smaller pores and advances along pore walls (Anderson 1987). Thus, the fraction of pore size increase as pore pressure increased for pores responsible for water flow might not have had a significant change on $K_{\mathrm{rw}}$. The behavior of the relative permeability curves in this pore pressure variation range could be compared in terms of pore sizes devoid of a significant wettability change. This observation is inconsistent with an earlier study of pore pressure variation at constant confining pressure presented by Al-Quraishi and Khairy (2005). In their work, a decreasing $K_{\mathrm{ro}}$ at the same saturation was observed with increased pore pressure within a similar range of $0.1,3.5$, and $6.9 \mathrm{MPa}$.

At relatively high pore pressure, a distinct behavior was observed. $K_{\mathrm{ro}}$ and $K_{\mathrm{rw}}$ significantly decreased and increased at constant saturation, respectively. This behavior was believed to be caused by wettability change. Increase in pore pressure changed the sample from water wet towards oil-wet conditions. Further proof of this is given in Sect. "Effect of pore pressure variation on end-point relative permeability for water-oil relative permeability curves". Increase in fluid pressure increases water-oil interfacial tension (Wang and Gupta 1995), thereby increasing the capillary pressure in the fluid system. When the capillary pressure exceeds the critical disjoining pressure, the thin water film coating the grain may break exposing the oil to a direct contact with the 
Table 4 Effect of nanoparticles on NMR $\mathrm{T}_{2}$ distribution

\begin{tabular}{|c|c|c|c|c|c|c|}
\hline $\begin{array}{l}\text { Time of NMR } \mathrm{T}_{2} \text { distribu- } \\
\text { tion measurement }\end{array}$ & Small pore area & Big pore area & Total pore area & $\begin{array}{l}\Delta \text { in small pore } \\
\text { area }(\%)^{\mathrm{b}}\end{array}$ & $\begin{array}{l}* \Delta \text { in big pore } \\
\text { area }(\%)\end{array}$ & $\begin{array}{l}* \Delta \text { in total } \\
\text { pore area }(\%)\end{array}$ \\
\hline \multicolumn{7}{|l|}{$\mathrm{F}-1$} \\
\hline Before water-oil ${ }^{\mathrm{a}}$ & 1.8596 & 1.4829 & 3.3425 & 0.00 & 0.00 & 0.00 \\
\hline After water-oil & 1.6081 & 1.3357 & 2.9438 & -15.64 & -11.02 & -13.54 \\
\hline Before nano-oil & 1.6081 & 1.3357 & 2.9438 & 0.00 & 0.00 & 0.00 \\
\hline After nano-oil & 1.5114 & 1.0297 & 2.5411 & -6.40 & -29.72 & -15.85 \\
\hline \multicolumn{7}{|l|}{$\mathrm{F}-2$} \\
\hline Before water-oil ${ }^{\mathrm{a}}$ & 1.6035 & 1.7817 & 3.3852 & 0.00 & 0.00 & 0.00 \\
\hline After water-oil & 1.5724 & 1.6754 & 3.2478 & -1.98 & -6.34 & -4.23 \\
\hline Before nano-oil & 1.5724 & 1.6754 & 3.2478 & 0.00 & 0.00 & 0.00 \\
\hline After nano-oil & 1.4364 & 1.2256 & 2.6620 & -9.47 & -36.70 & -22.01 \\
\hline \multicolumn{7}{|l|}{ F-3 } \\
\hline Before water-oil ${ }^{\mathrm{a}}$ & 0.6196 & 1.3843 & 2.0035 & 0.00 & 0.00 & 0.00 \\
\hline After water-oil & 0.5795 & 1.2989 & 1.8784 & -6.93 & -6.57 & -6.69 \\
\hline Before nano-oil & 0.5795 & 1.2989 & 1.8784 & 0.00 & 0.00 & 0.00 \\
\hline After nano-oil & 0.5350 & 0.8793 & 1.4143 & -8.305 & -47.73 & -32.81 \\
\hline \multicolumn{7}{|l|}{ F-4 } \\
\hline Before water-oil ${ }^{\mathrm{a}}$ & 0.6424 & 1.4107 & 2.0532 & 0.00 & 0.00 & 0.00 \\
\hline After water-oil & 0.6323 & 1.3622 & 1.9945 & -1.59 & -3.57 & -2.94 \\
\hline Before nano-oil & 0.6323 & 1.3622 & 1.9945 & 0.00 & 0.00 & 0.00 \\
\hline After nano-oil & 0.6535 & 1.0430 & 1.6965 & +3.23 & -30.60 & -17.57 \\
\hline
\end{tabular}

$\Delta$ : change

${ }^{\mathrm{a}} \mathrm{NMR} \mathrm{T}_{2}$ distribution represents the initial pore size distribution (see Table 4)

${ }^{\mathrm{b}}$ Negative values mean reduction in corresponding pore area, while positive values mean increment (see Table 4)

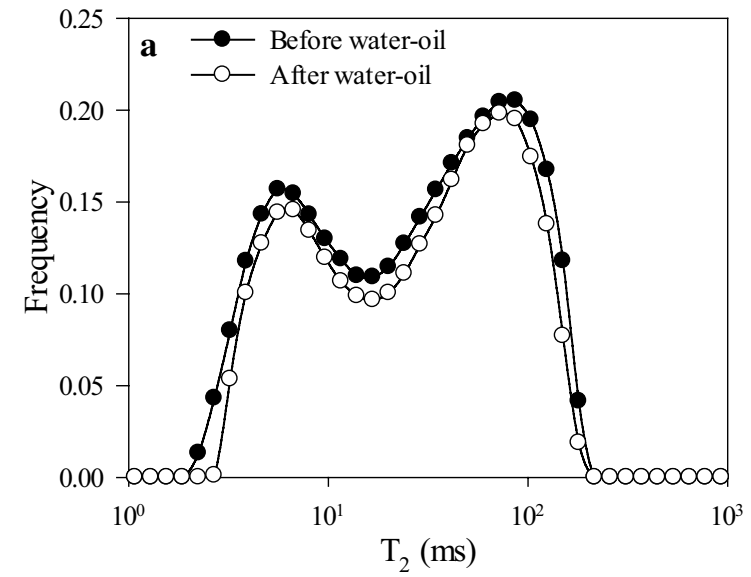

Fig. 5 NMR $T_{2}$ distribution for F-1

grain surface (Chattopadhyay et al. 2002), thereby altering wettability. The attachment of oil to grain surfaces lowers its flow significantly and water flows in relatively bigger pores, increasing its relative permeability.

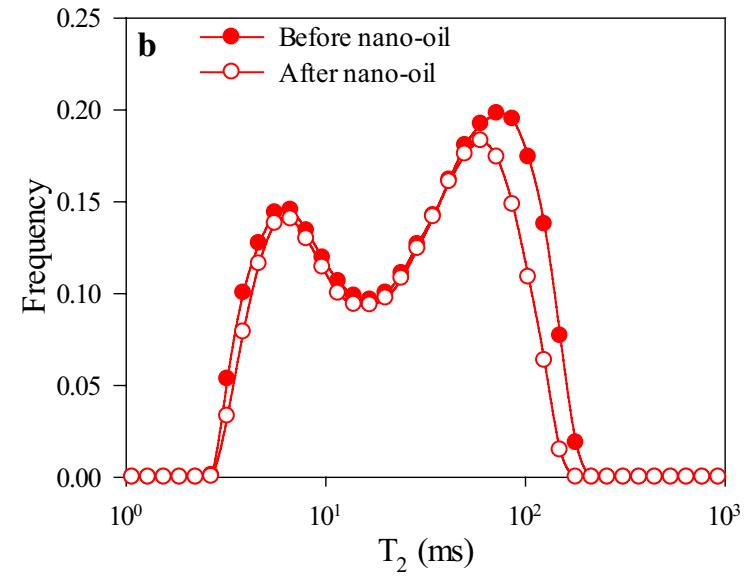

Effect of pore pressure variation on end-point saturations for water-oil relative permeability curves

In this study, the initial water saturation $\left(S_{\mathrm{wi}}\right)$ decreased with increasing pore pressure (decreasing net effective stress) for water-oil relative permeability (Fig. 9a, b; Table 5). At low pore pressures, the net effective stress on the samples would 
Fig. 6 NMR $\mathrm{T}_{2}$ distribution for F-2

Fig. 7 NMR $\mathrm{T}_{2}$ distribution for F-3

Fig. 8 NMR $\mathrm{T}_{2}$ distribution for F-4
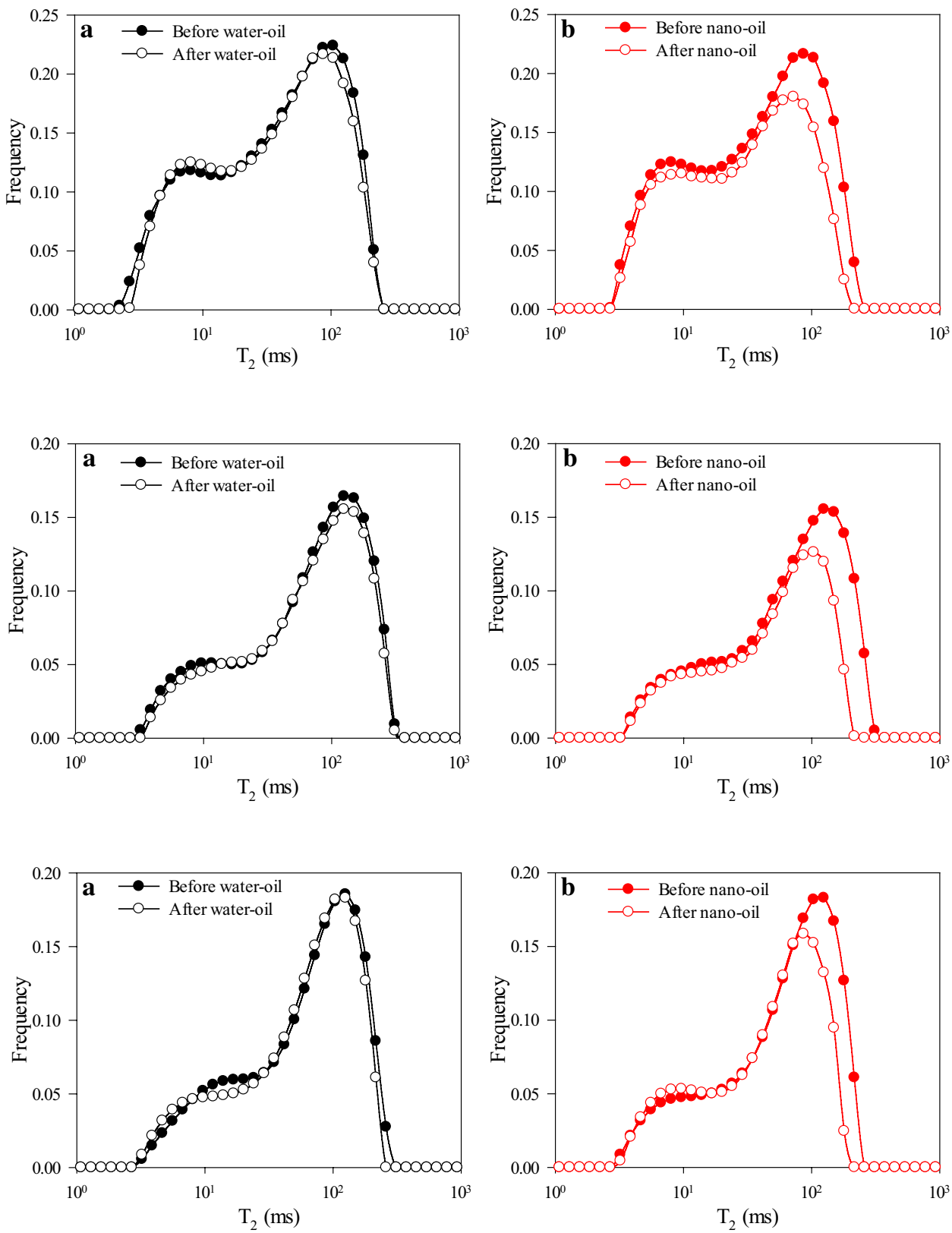

ideally be high, reducing pore volume, and increasing the fraction of smaller pores in the samples. More water would be held in these smaller pores by capillary forces. However, pore volume increased as pore pressure increased (Table 5). This implied some of the pores ideally enlarged. Samples with larger pores tend to have lower $S_{\text {wi }}$, because oil easily accesses most of the pores and less water is needed to wet pore surfaces (Morgan and Gordon 1970). In addition, with larger pores, capillary pressure is lowered and water could be readily released, reducing $S_{\mathrm{wi}}$.

It was observed that residual oil saturation $\left(S_{\text {or }}\right)$ decreased as pore pressure increased for the low pore pressure variations. However, at $10 \mathrm{MPa}$ pore pressure, $S_{\text {or }}$ significantly increased. Mobilization of residual oil out of a center of a pore requires that the capillary entry pressure for the local pore throat be lower than viscous forces (Peters 2012). At low pore pressures, effective stress was high and capillary entry pressure would be high due to smaller pore throats. As pore pressure increased, capillary entry pressure would reduce making it easier to mobilize oil. This was responsible for the observation made for pore pressure increment at 0.1 , 2 , and $5 \mathrm{MPa}$. The high and significant increase in $S_{\text {or }}$ for $10 \mathrm{MPa}$ may be due to oil-wet characteristics of the core sample. Thus, some of the oil was trapped in smaller pores by capillary forces and on the surfaces of grains.

The work presented by Al-Quraishi and Khairy (2005) agreed partially with some of the findings in this section. The authors observed a decrease in $S_{\text {wi }}$ at pore pressures 
Fig. 9 Effect of pore pressure variation on water-oil relative permeability: a low pore pressure range and $\mathbf{b}$ low-torelatively high pore pressure variation

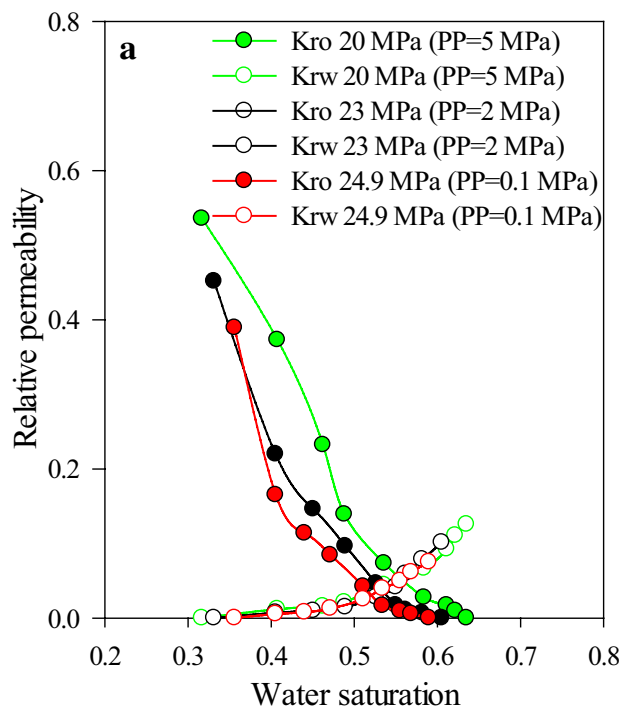

Table 5 Effect of pore pressure on end-point saturations, relative permeability, mobility ratio, and displacement efficiency

\begin{tabular}{|c|c|c|c|c|c|c|c|c|c|c|}
\hline Core sample & $\begin{array}{l}\text { Pore pres- } \\
\text { sure }(\mathrm{MPa})\end{array}$ & $S_{\mathrm{wi}}$ & $S_{\text {or }}$ & $K_{\mathrm{ro}}\left(S_{\mathrm{wi}}\right)$ & $K_{\mathrm{w}}\left(S_{\mathrm{or}}\right)$ & $1-S_{\mathrm{wi}}-S_{\text {or }}$ & $M$ & $E_{\mathrm{d}}$ & $\begin{array}{l}\text { Pore vol- } \\
\text { ume }(\mathrm{mL})\end{array}$ & $K_{\mathrm{a}}(\mathrm{mD})$ \\
\hline \multicolumn{11}{|c|}{ Water-oil (Run 1) } \\
\hline F-1 & 0.1 & 0.3560 & 0.4101 & 0.3890 & 0.0748 & 0.2339 & 0.3199 & 0.3632 & 4.62 & 17.5 \\
\hline $\mathrm{F}-2$ & 2 & 0.3313 & 0.3948 & 0.4516 & 0.1011 & 0.2739 & 0.3722 & 0.4095 & 4.66 & 21.6 \\
\hline F-3 & 5 & 0.3168 & 0.3647 & 0.5357 & 0.1255 & 0.3185 & 0.3894 & 0.4662 & 4.80 & 36.9 \\
\hline $\mathrm{F}-4$ & 10 & 0.3018 & 0.4399 & 0.3238 & 0.1529 & 0.2583 & 0.7854 & 0.3700 & 4.87 & 32.2 \\
\hline \multicolumn{11}{|c|}{ Nanofluid-oil (Run 2) } \\
\hline F-1 & 0.1 & 0.3487 & 0.3466 & 0.3814 & 0.0996 & 0.3047 & 0.3449 & 0.4678 & 4.60 & 19.5 \\
\hline $\mathrm{F}-2$ & 2 & 0.3316 & 0.3156 & 0.4497 & 0.1383 & 0.3528 & 0.4063 & 0.5278 & 4.64 & 23.6 \\
\hline F-3 & 5 & 0.3097 & 0.2889 & 0.5548 & 0.1748 & 0.4014 & 0.4164 & 0.5815 & 4.77 & 34.0 \\
\hline F-4 & 10 & 0.3055 & 0.3271 & 0.3292 & 0.1109 & 0.3673 & 0.4453 & 0.5290 & 4.87 & 36.6 \\
\hline
\end{tabular}

of $0.1,3.5$, and 6.9 $\mathrm{MPa}$, but an increase at $13.8 \mathrm{MPa} . S_{\text {or }}$, however, showed complicated behavior.

\section{Effect of pore pressure variation on end-point relative permeability for water-oil relative permeability curves}

The study revealed that, for low pore pressure increments, both oil end-point relative permeability $\left[K_{\mathrm{ro}}\left(S_{\mathrm{wi}}\right)\right]$ and water end-point relative permeability $\left[K_{\mathrm{rw}}\left(S_{\mathrm{or}}\right)\right]$ increased. At $10 \mathrm{MPa}$ pore pressure, $K_{\mathrm{ro}}\left(S_{\mathrm{wi}}\right)$ significantly reduced and $K_{\text {rw }}\left(S_{\text {or }}\right)$ increased to a maximum.

The reasons for the observations in Sect. "Effect of pore pressure variation on water-oil relative permeability" for changes in $K_{\text {ro }}$ curves for both low and relatively high pore pressure variation could be attributed to the behavior observed for $K_{\text {ro }}\left(S_{\mathrm{wi}}\right)$ changes with pore pressure. However, at $S_{\text {or }}$, water flows along pore walls and in voids created by displaced oil (Abdallah et al. 1986; Anderson 1987). As pore pressure increased, more oil was produced evident as a corresponding reduction in $S_{\text {or }}$ (Table 5). This created more voids for water to flow and could be responsible for the increase in $K_{\mathrm{rw}}\left(S_{\mathrm{wi}}\right)$ with pore pressure at low pore pressure variations.

It was stated in Sect. "Effect of pore pressure variation on water-oil relative permeability" and "Effect of pore pressure variation on end-point saturations for water-oil relative permeability curves" that wettability alterations could cause the disparity caused at $10 \mathrm{MPa}$ pore pressure. The third rule of thumb proposed by Craig (1971) was applied to investigate possible wettability changes. Therefore, $K_{\mathrm{rw}}\left(S_{\mathrm{or}}\right)$ was normalized by $K_{\text {ro }}\left(S_{\text {wi }}\right)$ at all pore pressures. For $0.1,2$, and $5 \mathrm{MPa}$ the normalized floodout $K_{\mathrm{rw}}\left(S_{\mathrm{or}}\right)$ were 0.1924 , 0.2238 , and 0.2341 , respectively. However, at $10 \mathrm{MPa}$ pore pressure, the normalized floodout $K_{\text {rw }}\left(S_{\text {or }}\right)$ was 0.4723 . According to Craig (1971), a floodout $K_{\mathrm{rw}}\left(S_{\mathrm{or}}\right)$ less than 0.3 is water wet and that greater than 0.5 is oil wet. It is obvious that, following this rule of thumb, at $0.1,2$, and $5 \mathrm{MPa}$ pore pressures, the samples were water wet and thus exhibited 
consistent behavior with pore pressure variation. At $10 \mathrm{MPa}$ pore pressure, however, the sample tend to approach oilwet characteristics. This finding supported the explanations given in Sect. "Effect of pore pressure variation on water-oil relative permeability" and "Effect of pore pressure variation on end-point saturations for water-oil relative permeability curves".

\section{Effect of pore pressure variation on nanofluid-oil relative permeability}

Similarly, for nanofluid-oil relative permeability, at low pore pressure range $(0.1,2$, and $5 \mathrm{MPa})$, the curves displayed consistent behavior, but distinct characteristics were observed at relatively high pore pressure of $10 \mathrm{MPa}$.

Increasing pore pressure within the low range, $K_{\mathrm{ro}}$ curves increased significantly while $K_{\mathrm{rw}}$ curves had fair increments at constant saturation (Fig. 10). The increment in $K_{\text {ro }}$ curves could be explained in a similar way as that for water-oil relative permeability in Sect. "Effect of pore pressure variation on water-oil relative permeability". Unlike the $K_{\mathrm{rw}}$ curves for water-oil relative permeability that did not display obvious changes, for nanofluid-oil relative permeability $K_{\text {rw }}$ curves showed fair increments at constant saturation. This was probably because more oil was displaced from the center of pores in the nanofluid-oil (Run 2) compared to water-oil (Run 1) (Run 2 has a lower $S_{\text {or }}$ than Run 1 at the same pore pressure; see Table 5). More oil produced implied more voids were created for fluid flow. Wetting phase flows along pore walls and progressively invades larger pores (Anderson 1987). Therefore, as pore pressure increased, pore size ideally increased reducing capillary pressure which produced more oil and made water flow easier.

At $10 \mathrm{MPa}$ pore pressure, and at higher water saturation, $K_{\mathrm{ro}}$ curve was a bit higher than the $0.1 \mathrm{MPa} K_{\mathrm{ro}}$ curve.
The $K_{\mathrm{rw}}$ curves also tracked between that of $2 \mathrm{MPa}$ and $0.1 \mathrm{MPa}$ pore pressure curves. This could be due to wettability change. Hydrophilic silica nanoparticles have been established as wettability modifiers making oil-wet rocks water wet (Lu et al. 2017). Since the trend of $K_{\text {ro }}\left(S_{\text {wi }}\right)$ was the same as that of water-oil relative permeability, it was deduced that, during the drainage process, oil might have made the sample tend oil wet as described in Sect. "Effect of pore pressure variation on water-oil relative permeability". However, during the imbibition process, the silica nanofluid might have rendered the core sample water wet.

\section{Effect of pore pressure variation on end-point saturations for nanofluid-oil relative permeability curves}

The trend revealed for $S_{\mathrm{wi}}$ with pore pressure was the same as that observed for water-oil relative permeability (Run1) (Figs. 10, 12a). Since determination of $S_{\mathrm{wi}}$ followed the same protocol as in Run 1, the same explanation as that given in Sect. "Effect of pore pressure variation on end-point saturations for water-oil relative permeability curves" could be attributed to this observation.

In addition, $S_{\text {or }}$ variation for low pore pressure increment was similar to Run 1 and the same reasons given in Sect. "Effect of pore pressure variation on end-point saturations for water-oil relative permeability curves" could be given to this finding. However, at $10 \mathrm{MPa}$ pore pressure, $S_{\text {or }}$ was between that of $0.1 \mathrm{MPa}$ and $2 \mathrm{MPa}$. For Run 1, $S_{\text {or }}$ was highest at this pore pressure and it was revealed that the wettability of the sample approached strongly oilwet status. However, introduction of hydrophilic silica nanoparticles probably changed this status to water wet which could be responsible for more oil production and reduction in $S_{\text {or. }}$.
Fig. 10 Effect of pore pressure variation on nanofluid-oil relative permeability: a low pore pressure range and $\mathbf{b}$ low-torelatively high pore pressure variation
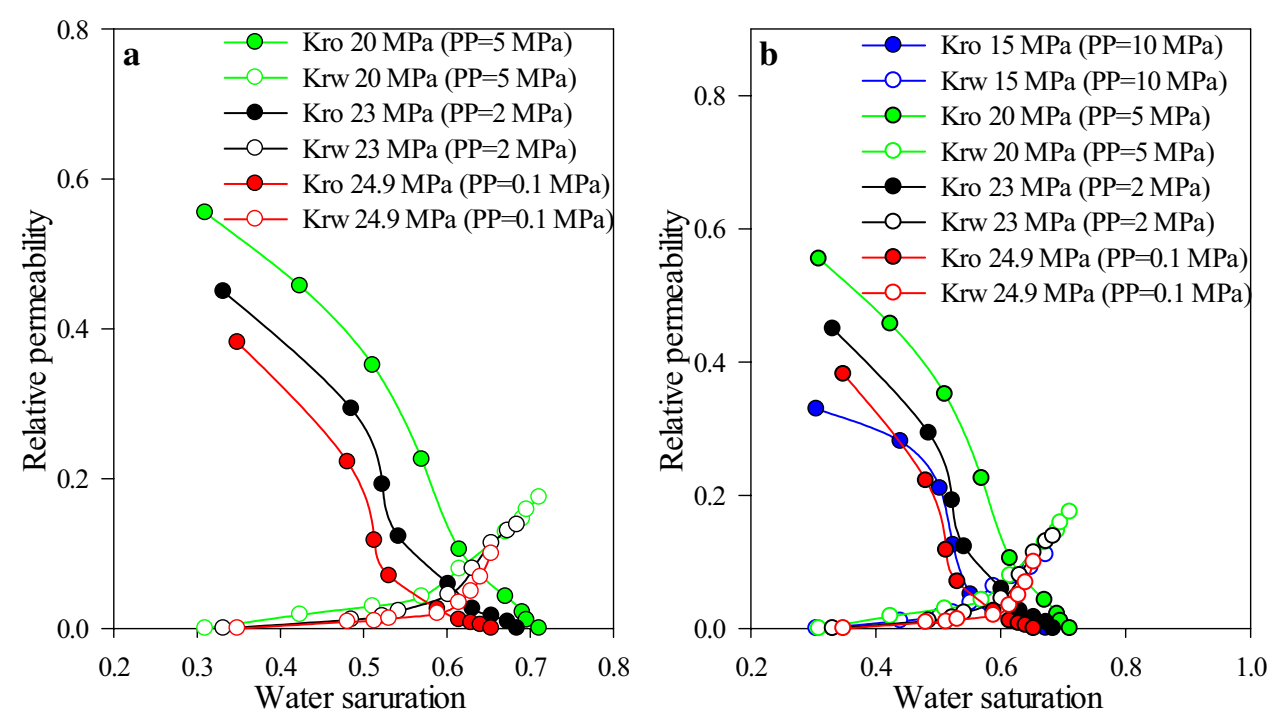
Fig. 11 Comparison of wateroil and nanofluid-oil relative permeability under stress: a $10 \mathrm{MPa}$, b $5 \mathrm{MPa}$, c $2 \mathrm{MPa}$, and d $0.1 \mathrm{MPa}$
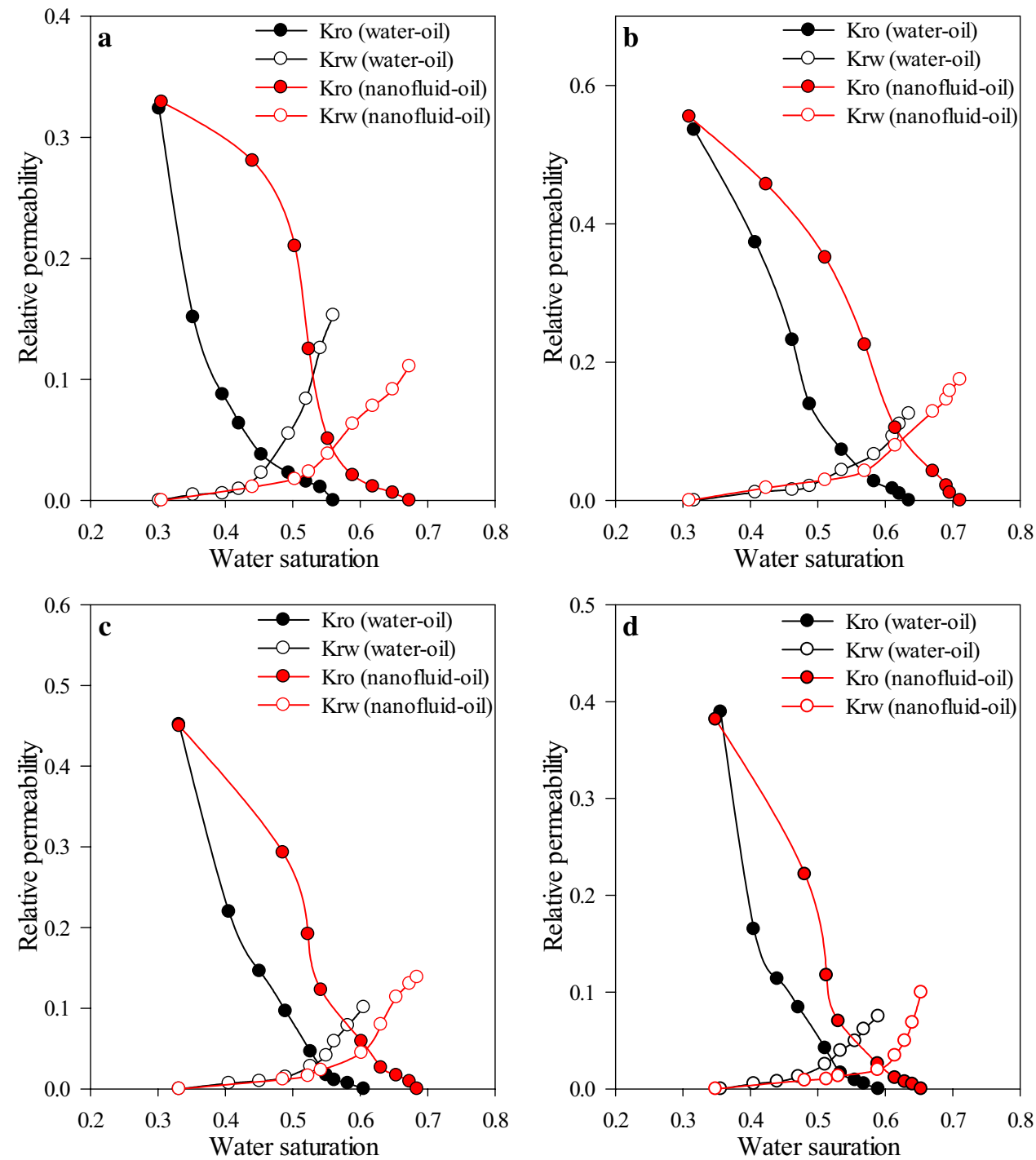
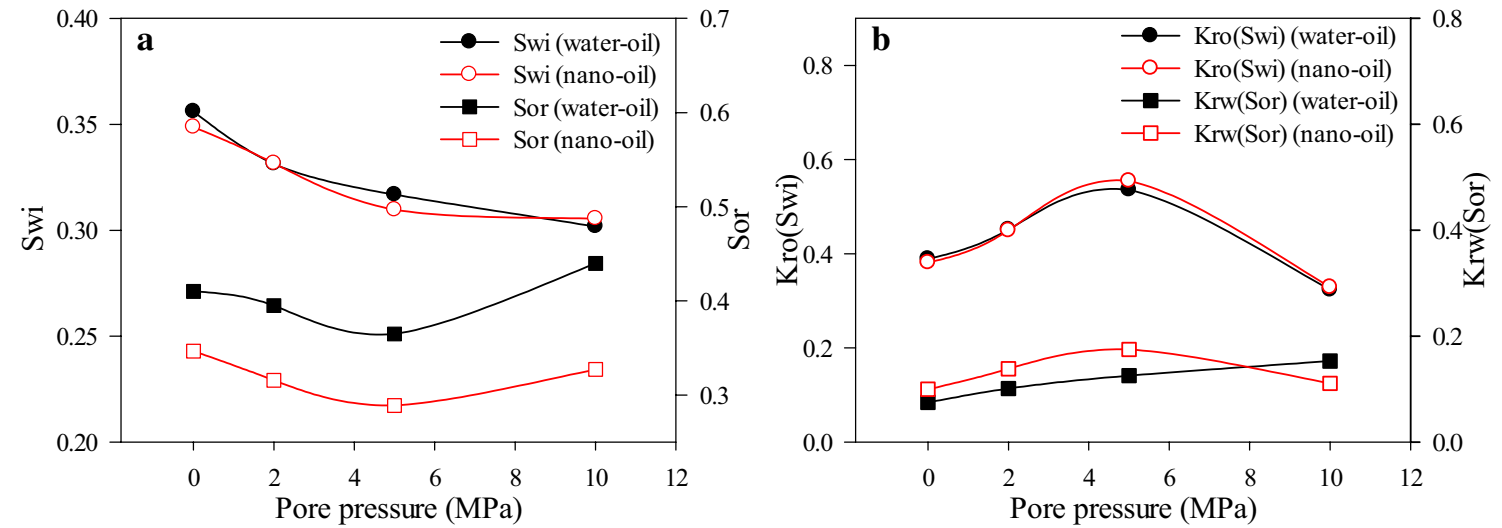

Fig. 12 Effect of pore pressure on $\mathbf{a}$ end-point saturations and $\mathbf{b}$ end-point relative permeability 


\section{Effect of pore pressure variation on end-point relative permeability for nanofluid-oil relative permeability curves}

$K_{\mathrm{ro}}\left(S_{\mathrm{wi}}\right)$ had a similar trend as that for Run 1, as depicted in Fig. 12. Since the drainage process was the same for that of Run 1, similar results were expected and the same reasons given in Sect. "Effect of pore pressure variation on endpoint relative permeability for water-oil relative permeability curves" could be attributed to this behavior.

$K_{\mathrm{rw}}\left(S_{\mathrm{or}}\right)$ increased for low pore pressure increment, but decreased at $10 \mathrm{MPa}$. During the low pore pressure variation, the samples could be compared in terms of pore sizes. Increase in pore pressure increased pore sizes and this lowered capillary entry pressure, and thus, more oil was mobilized out of pores. This argument was corroborated by the lower $S_{\text {or }}$ displayed (Table 5; Fig. 10a). Therefore, there were more voids created for water to flow at $S_{\text {or }}$ resulting in increase in $K_{\mathrm{rw}}\left(S_{\mathrm{or}}\right)$ within this pore pressure increment range. However, at $10 \mathrm{MPa}$, the wettability differences could probably be responsible for such an observation. Using the third rule of Craig and normalizing $K_{\mathrm{rw}}\left(S_{\mathrm{or}}\right)$ by $K_{\mathrm{ro}}\left(S_{\mathrm{wi}}\right)$ resulted in 0.3370. Compared to that of Run 1, this value decreased at $10 \mathrm{MPa}$ and it was as a result of the silica nanofluid which reduced the oil wetness close to water wetness. The sample could, therefore, be in mixed-wet conditions.

\section{Comparison of water-oil and nanofluid-oil relative permeability}

Figure 11 presents results for water-oil and nanofluid-oil relative permeability curves under the same pore pressure, while Fig. 12 presents variations in end-point relative permeability and end-point saturations for water-oil and nanofluid-oil runs.

From Fig. 11, it was observed that, at the same saturation, $K_{\mathrm{ro}}$ curves were higher for water-oil than nanofluid-oil. Thus, oil flow was higher in the nanofluid flooding than in water flooding. Increased recovery with silica nanofluids is due to reduction in interfacial tension (Torsater et al. 2012). This would reduce capillary entry pressure and aid in oil mobilization from small pores. Furthermore, structural disjoining pressure is increased when nanoparticles are employed and this helps in the spread of nanofluid on rock surfaces which aids in more oil production (Chengara et al. 2004; Wasan and Nikolov 2003). This same explanation was also responsible for the lower $S_{\text {or }}$ observed in nanofluid flooding as compared to water flooding (Figs. 11, 12a).

At lower but same water saturation, $K_{\mathrm{rw}}$ curves were lower for nanofluid-oil than water-oil for all pore pressures. Wetting phase flows through relatively small pores (Abdallah et al. 1986), and at lower saturations, nanoparticles could coagulate and block those pores making injection and flow more difficult. This would reduce $K_{\mathrm{rw}}\left(S_{\mathrm{or}}\right)$. However, as wetting phase increased, more oil was produced out of larger pores which created more flow paths making $K_{\text {rw }}$ higher at higher saturations. The same reason could be given for the significantly higher $K_{\mathrm{rw}}\left(S_{\mathrm{or}}\right)$ in nanofluid flooding compared to water flooding.

Since the drainage process was the same for both water-oil and nanofluid--oil relative permeabilities, $S_{\mathrm{wi}}$ and $K_{\mathrm{ro}}\left(S_{\mathrm{wi}}\right)$ were similar (Fig. 12). The crossover point between $K_{\mathrm{ro}}$ and $K_{\mathrm{rw}}$ occurred at higher wetting phase saturation for nanofluid flooding as compared to water flooding. An important revelation in Fig. 12 was that for 0.1, 2, and $5 \mathrm{MPa}$ pore pressures $S_{\mathrm{wi}}, S_{\mathrm{or}}, K_{\mathrm{ro}}\left(S_{\mathrm{wi}}\right)$, and $K_{\mathrm{rw}}\left(S_{\mathrm{or}}\right)$ had similar trends as pore pressure increased within this range. The behavior of all the above parameters at $10 \mathrm{MPa}$, however, differs from the observations made in the low pore pressure range. In Sect. "Effect of pore pressure variation on end-point relative permeability for water-oil relative permeability curves", it was revealed that the samples exhibited water-wet conditions but an almost strongly oil-wet condition at $10 \mathrm{MPa}$. Therefore, at low pore pressure range, behavior of samples could be compared in terms of pore size change, while, at $10 \mathrm{MPa}$, behavior of parameters and curves of relative permeability could be due to wettability change.

\section{Effect of pore pressure on end-point mobility ratio and displacement efficiency for different displacing fluids}

Evaluation of end-point mobility ratio and displacement efficiency was carried out according to equations and theories presented in Online Resource B.3. End-point mobility ratio and displacement efficiency for increasing pore pressure are illustrated in Fig. 13. It was revealed that end-point mobility ratios for all displacements were less than 1 and increased with increase in pore pressure. However, nanofluid flooding had higher end-point mobility ratio in low pore pressure variation range, but, at $10 \mathrm{MPa}$, mobility ratio was less than that of water flooding. Displacement efficiency increased in the low pressure pore pressure variation range, but decreased at $10 \mathrm{MPa}$ for both water and nanofluid flooding. Moreover, displacement efficiency was higher in nanofluid flooding than water flooding for all pore pressures.

As pore pressure increased for water flooding, $K_{\mathrm{rw}}\left(S_{\mathrm{or}}\right)$ increased, and although there was increase in $K_{\mathrm{ro}}\left(S_{\mathrm{wi}}\right)$, the percent changes in $K_{\text {ro }}\left(S_{\text {wi }}\right)$ were lower. This increased endpoint mobility ratio in the low pore pressure range. This same explanation holds for nanofluid flooding for all pore pressures. Therefore, as pore pressure increased, water flow became easier compared to oil, rendering slower flow of oil relative to water. The abnormally high end-point mobility ratio for water flooding at $10 \mathrm{MPa}$ was because of wettability change that caused water to flow in bigger pores, while oil attached itself to grains in oil-wet circumstances. 
Fig. 13 Effect of pore pressure on a end-point mobility ratio and $\mathbf{b}$ displacement efficiency
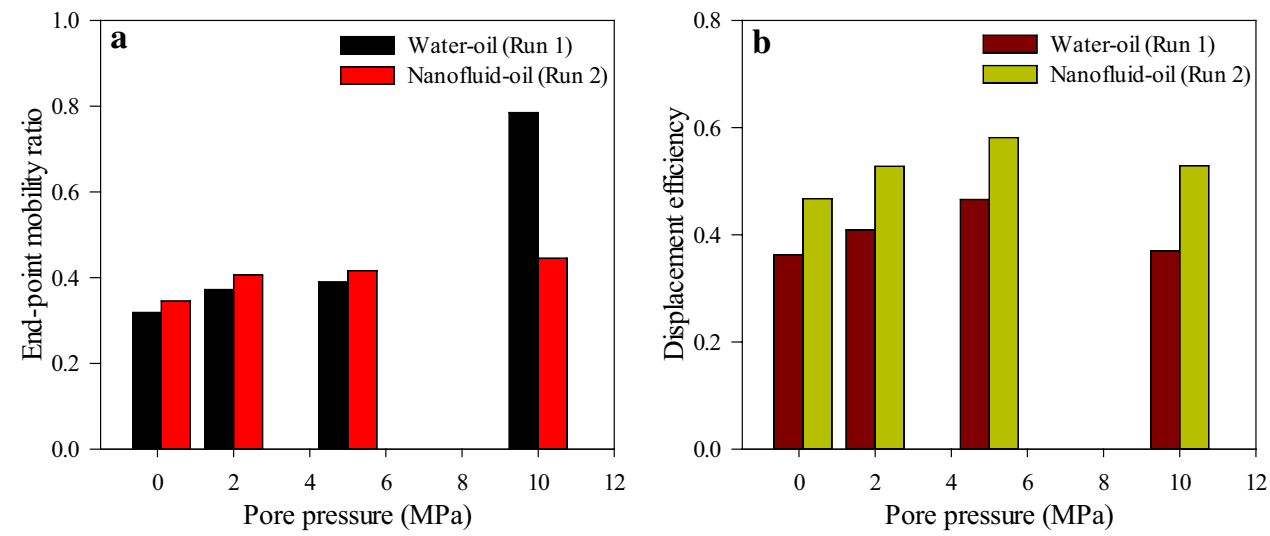

$K_{\mathrm{rw}}\left(S_{\mathrm{or}}\right)$, thus, increased significantly. Oil flow was very difficult compared to water flow, making water flow faster relative to oil for water flooding at $10 \mathrm{MPa}$. Although viscosity increased due to addition of nanoparticles, $K_{\mathrm{rw}}\left(S_{\mathrm{or}}\right)$ was higher at each pore pressure for nanofluid flooding compared to water flooding, making end-point mobility ratio higher except for $10 \mathrm{MPa}$ pore pressure.

The observed trend in displacement efficiency was due to changes in $S_{\text {or }}$ Pore pressure increment reduced $S_{\text {or }}$ for the low pore pressure range which had similar wettability. However, at $10 \mathrm{MPa}$ due to significant $S_{\text {or }}$ recorded in water flooding, displacement efficiency reduced significantly. This also corroborates earlier claims of wettability change. The higher displacement efficiency observed for nanofluid flooding was as a result of lower $S_{\text {or }}$ compared to water flooding. This implied that it was easier to produce more oil with nanofluid at the microscopic scale.

\section{Conclusions}

This research studied the effect of pore pressure variation at constant confining stress on relative permeability and twophase flow parameters using water and silica nanofluid as displacing fluids. The following conclusions can be drawn:

1. At $0.1,2$, and $5 \mathrm{MPa}$ pore pressures (low pore pressure variation), the sample could be compared based on pore size variation as pore pressure increased devoid of significant wettability change.

(i) $S_{\mathrm{wi}}$ and $S_{\text {or }}$ decreased as pore pressure increased. $K_{\mathrm{ro}}\left(S_{\mathrm{wi}}\right)$ and $K_{\mathrm{rw}}\left(S_{\mathrm{or}}\right)$ both increased for water flooding. Similar trends were also observed for nanofluid flooding.

(ii) End-point mobility ratio and displacement efficiency both increased with increase in pore pressure for water as well as nanofluid flooding.
2. Relatively high pore pressure (10 $\mathrm{MPa})$ rendered the sample towards oil wetness. Comparing trends to low pore pressure variation, samples could be compared in terms of wettability alteration.

(i) $I S_{\mathrm{wi}}$ decreased compared to low pore pressure variation; however, $S_{\text {or }}$ increased significantly. The same observation was made for nanofluid flooding except for $S_{\text {or }}$ which had moderate increment.

(ii) End-point mobility ratio increased significantly for water flooding, but had a slight increase for nanofluid flooding compared with low pore pressure variation. Displacement efficiency decreased for both water and nanofluid flooding compared with low pore pressure variation.

3. At the same pore pressure, water-oil and nanofluid-oil relative permeabilities showed similar $S_{\mathrm{wi}}$ and $K_{\mathrm{ro}}\left(S_{\mathrm{wi}}\right)$ but differing $\mathrm{S}_{\text {or }}$ and $K_{\mathrm{rw}}\left(S_{\mathrm{or}}\right)$.

4. End-point mobility ratio was higher in nanofluid flooding except for $10 \mathrm{MPa}$ pore pressure. Displacement efficiency was higher in nanofluid flooding compared to water flooding.

Acknowledgements The authors would like to express their profound gratitude to Dr. Philip Antwi and Dr. Samuel Barnie for their help in the preparation of this manuscript. This research was supported by the National Science and Technology Major Project of China (Grant Number 2017ZX05009-005).

Open Access This article is distributed under the terms of the Creative Commons Attribution 4.0 International License (http://creativeco mmons.org/licenses/by/4.0/), which permits unrestricted use, distribution, and reproduction in any medium, provided you give appropriate credit to the original author(s) and the source, provide a link to the Creative Commons license, and indicate if changes were made. 


\section{References}

Abdallah W, Buckley JS, Carnegie A, Edwards J, Herold B, Fordham E, Graue A, Habashy T, Seleznev N, Signer C (1986) Fundamentals of wettability. Technology 38(1125-1144):268

Abdelazim R (2016) An integrated approach for relative permeability estimation of fractured porous media: laboratory and numerical simulation studies. J Pet Explor Prod Technol. https://doi. org/10.1007/s13202-016-0250-x

Adenutsi CD, Li Z, Aggrey WN, Toro BL (2018) Performance of relative permeability and two-phase flow parameters under net effective stress in water wet porous media: a comparative study of water-oil versus silica nanofluid-oil. Arab J Sci Eng 43(11):6555-6565

Afolabi RO, Yusuf EO (2018) Nanotechnology and global energy demand: challenges and prospects for a paradigm shift in the oil and gas industry. J Pet Explor Prod Technol. https://doi. org/10.1007/s13202-018-0538-0

Akhlaghinia M, Torabi F, Chan CW (2014) Experimental investigation of temperature effect on three-phase relative permeability isoperms in heavy oil systems. Fuel 118:281-290

Ali H, Al-Marhoun M, Abu-Khamsin S, Celik M (1987) The effect of overburden pressure on relative permeability, society of petroleum engineers. In: SPE fifth middle east oil show, 7-10 March, Manama, Bahrain, SPE-15730-MS

Al-Quraishi A, Khairy M (2005) Pore pressure versus confining pressure and their effect on oil-water relative permeability curves. J Pet Sci Eng 48(1):120-126

Amedi H, Ahmadi M-A (2016) Experimental investigation the effect of nanoparticles on the oil-water relative permeability. Eur Phys J Plus 131(5):1-8

Anderson WG (1987) Wettability literature survey part 5: the effects of wettability on relative permeability. J Pet Technol 39(11):1453-451468

Chattopadhyay S, Jain V, Sharma M (2002) Effect of capillary pressure, salinity, and aging on wettability alteration in sandstones and limestones. In: SPE/DOE improved oil recovery symposium. 13-17 April, Tulsa, Oklahoma, SPE-75189-MS

Chengara A, Nikolov AD, Wasan DT, Trokhymchuk A, Henderson D (2004) Spreading of nanofluids driven by the structural disjoining pressure gradient. J Colloid Interf Sci 280(1):192-201

Cheraghian G (2015) Effects of nanoparticles on wettability: a review on applications of nanotechnology in the enhanced oil recovery. Int J Nano Dimens 6(5):443

Cheraghian G, Hendraningrat L (2016a) A review on applications of nanotechnology in the enhanced oil recovery part A: effects of nanoparticles on interfacial tension. Int Nano Lett 6(2):129-138

Cheraghian G, Hendraningrat L (2016b) A review on applications of nanotechnology in the enhanced oil recovery part B: effects of nanoparticles on flooding. Int Nano Lett 6(1):1-10

Craig FF (1971) The reservoir engineering aspects of waterflooding. HL Doherty Memorial Fund of AIME, New York

Fatt I (1953) The effect of overburden pressure on relative permeability. J Pet Technol 5(10):15-16

Gawish A, Al-Homadhi E (2008) Relative permeability curves for high pressure, high temperature reservoir conditions. Oil Gas Bus 2:23

Giraldo J, Benjumea P, Lopera S, Cortés FB, Ruiz MA (2013) Wettability alteration of sandstone cores by alumina-based nanofluids. Energy Fuels 27(7):3659-3665

Gupta R, Maloney DR (2016) Intercept method-a novel technique to correct steady-state relative permeability data for capillary end effects. SPE Reserv Eval Eng 19(02):316-330

Hassler G, Brunner E (1945) Measurement of capillary pressures in small core samples. Trans AIME 160(01):114-123
Jones C, Al-Quraishi A, Somerville J, Hamilton S (2001) Stress sensitivity of saturation and end-point relative permeabilities. Society of core analysts, Edinburgh

Ju B, Fan T (2009) Experimental study and mathematical model of nanoparticle transport in porous media. Powder Technol 192(2):195-202

Ju B, Dai S, Luan Z, Zhu T, Su X, Qiu X (2002) A study of wettability and permeability change caused by adsorption of nanometer structured polysilicon on the surface of porous media. In: SPE Asia Pacific oil and gas conference and exhibition, 8-10 October, Melbourne, Australia, SPE-77938-MS

Ju B, Fan T, Li Z (2012) Improving water injectivity and enhancing oil recovery by wettability control using nanopowders. J Pet Sci Eng 86:206-216

Li F, Yang S, Chen H, Zhang X, Yin D, He L, Wang Z (2015) An improved method to study $\mathrm{CO}_{2}$-oil relative permeability under miscible conditions. J Pet Explor Prod Technol 5(1):45-53

Lu T, Li Z, Zhou Y, Zhang C (2017) Enhanced oil recovery of low-permeability cores by $\mathrm{SiO}_{2}$ nanofluid. Energy Fuels 31(5):5612-5621

Morgan J, Gordon D (1970) Influence of pore geometry on water-oil relative permeability. J Pet Technol 22(10):1199-191208

Parvazdavani M, Masihi M, Ghazanfari MH (2014) Monitoring the influence of dispersed nano-particles on oil-water relative permeability hysteresis. J Petrol Sci Eng 124:222-231

Parvazdavani M, Abbasi S, Zare-Reisabadi M (2017) Experimental study of gas-oil relative permeability curves at immiscible/near miscible gas injection in highly naturally fractured reservoir. Egypt J Pet 26(1):171-180

Peters EJ (2012) Advanced petrophysics: volume 2: dispersion, interfacial phenomena/wettability, capillarity/capillary pressure, relative permeability. Greenleaf Book Group, Austin, p 276

Roustaei A, Bagherzadeh $\mathrm{H}$ (2015) Experimental investigation of $\mathrm{SiO}_{2}$ nanoparticles on enhanced oil recovery of carbonate reservoirs. J Pet Explor Prod Technol 5(1):27-33

Roustaei A, Saffarzadeh S, Mohammadi M (2013) An evaluation of modified silica nanoparticles' efficiency in enhancing oil recovery of light and intermediate oil reservoirs. Egypt J Pet 22(3):427-433

Shi S, Belhaj H, Bera A (2018) Capillary pressure and relative permeability correlations for transition zones of carbonate reservoirs. J Pet Explor Prod Technol 8(3):767-784

Sun X, Zhang Y, Chen G, Gai Z (2017) Application of nanoparticles in enhanced oil recovery: a critical review of recent progress. Energies 10(3):345

Thomas RD, Ward DC (1972) Effect of overburden pressure and water saturation on gas permeability of tight sandstone cores. J Pet Technol 24(02):120-124

Tian X, Cheng L, Yan Y, Liu H, Zhao W, Guo Q (2015) An improved solution to estimate relative permeability in tight oil reservoirs. J Pet Explor Prod Technol 5(3):305-314

Torsater O, Engeset B, Hendraningrat L, Suwarno S (2012) Improved oil recovery by nanofluids flooding: an experimental study. In: SPE Kuwait international petroleum conference and exhibition, 10-12 December, Kuwait City, Kuwait, SPE-163335-MS

Wang W, Gupta A (1995) Investigation of the effect of temperature and pressure on wettability using modified pendant drop method. In: SPE annual conference and exhibition, 22-25 October, Dallas, Texas, SPE-30544-MS

Wasan DT, Nikolov AD (2003) Spreading of nanofluids on solids Nature 423(6936): 156

Wilson J (1956) Determination of relative permeability under simulated reservoir conditions. AIChE J 2(1):94-100

Youssif MI, El-Maghraby RM, Saleh SM, Elgibaly A (2018) Silica nanofluid flooding for enhanced oil recovery in sandstone rocks. Egyptian J Pet 27(1):105-110 
Zallaghi M, Kharrat R, Hashemi A (2018) Improving the microscopic sweep efficiency of water flooding using silica nanoparticles. J Pet Explor Prod Technol 8(1):259-269

Zhang H, He S, Jiao C, Luan G, Mo S, Guo X (2014) Determination of dynamic relative permeability in ultra-low permeability sandstones via X-ray CT technique. J Pet Explor Prod Technol 4(4):443-455
Publisher's Note Springer Nature remains neutral with regard to jurisdictional claims in published maps and institutional affiliations. 